\title{
Forcing Independent Spectrum in Graphs
}

\author{
A.P.Pushpalatha \\ Assistant Professor \\ Department of Mathematics \\ Thiagarajar College of \\ Engineering, Madurai-625015
}

\author{
G.Jothilakshmi \\ Assistant Professor \\ Department of Mathematics \\ Thiagarajar College of \\ Engineering, Madurai-625015
}

\author{
S.Suganthi, \\ V.Swaminathan \\ Ramanujan Research Centre, \\ Saraswathi Narayanan \\ College, Madurai-625022
}

\begin{abstract}
Let $\mathrm{G}=(\mathrm{V}, \mathrm{E})$ be a simple graph. Let $\mathrm{S}$ be a maximum independent set of G. A subset $\mathrm{T}$ of $\mathrm{S}$ is called a forcing subset if $\mathrm{T}$ is contained in no other maximum independent subset in G. The independent forcing number of $S$ denoted by $f_{I}(G, S)$ is the cardinality of a minimum forcing subset of $S$. The independent forcing number of $G$ is the minimum of the independent forcing number of $S$, where $S$ is a maximum independent subset in G. The independent forcing spectrum of $G$ denoted by $\operatorname{Spec}_{I}(G)$ is defined as the set $\operatorname{Spec}_{\mathrm{I}}(\mathrm{G})=\{\mathrm{k}$ : there exists a maximum independent set $\mathrm{S}$ of $\mathrm{G}$ such that $\left.\mathrm{f}_{\mathrm{I}}(\mathrm{G}, \mathrm{S})=\mathrm{k}\right\}$. In this paper, a study of $\operatorname{Spec}_{\mathrm{I}}(\mathrm{G})$ is made..
\end{abstract}

\section{Keywords}

Forcing domination number of a graph, Forcing spectrum of a graph and Forcing independent spectrum of a graph.

\section{INTRODUCTION}

The forcing sets in a graph are a very interesting concept. In the management of an institution, the executive committee consists of senior members who have adequate rapport with other members of the institution. Some members of the executive committee may sit in other important committees also. Sometimes, restrictions are imposed on members that they can be part of exactly one committee. This precisely leads to the concept of forcing set. A subset of a minimum dominating set $\mathrm{S}$ is called a forcing subset with respect to $\mathrm{S}$ if this subset is contained in no other minimum dominating set of G.Many authors have studied this forcing concept with respect to several parameters like domination ,matching ,geodetic domination, chromatic partition, etc. This chapter studies the forcing concept with respect to maximum independence. A subset of a maximum independent set may be contained in other maximum independent sets also. For example, in $\mathrm{C}_{5}$, every vertex is contained in at least two maximum independent sets. The natural curiosity is to study such subsets which are constrained to remain only in one maximum independent set which is forced to remain only in that set. We consider only finite, simple and undirected graphs $\mathrm{G}=(\mathrm{V}, \mathrm{E}) \cdot[2]$ Gary Chartered, Gavlas and Robert C.Vandell introduced the concept of Forcing domination number of a graph.

\subsection{Definition}

[2] A subset $\mathrm{T}$ of a minimum dominating set $\mathrm{S}$ is a forcing Subset for $\mathrm{S}$ if $\mathrm{S}$ is the unique minimum dominating set containing $\mathrm{T}$. $\mathrm{S}$ is called the forcing dominating set of $\mathrm{T}$. The minimum cardinality among the forcing subsets of $\mathrm{S}$ is called the forcing domination number of $\mathrm{S}$ and is denoted by $\mathrm{f}(\mathrm{S}, \gamma$ (G)). The minimum forcing domination number among the minimum dominating sets of $\mathrm{G}$ is denoted by $\mathrm{f}(\mathrm{G}, \gamma)$. That is $\mathrm{f}(\mathrm{G}, \gamma)=\min \mathrm{f}\left(\mathrm{S}_{\mathrm{i}}, \gamma\right)$, where $\mathrm{S}_{\mathrm{i}}$ 's are the minimum dominating set of G. Cleary, for any graph $\mathrm{G}, \mathrm{f}(\mathrm{G}, \gamma) \leq \gamma(\mathrm{G})$.

\subsection{Defintion}

[1] Let $\mathrm{G}$ be a simple graph. The forcing spectrum of $\mathrm{G}$ denoted

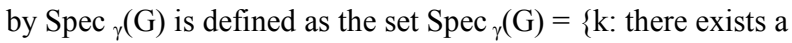
minimum dominating set $\mathrm{S}$ of $\mathrm{G}$ such that $\mathrm{f}(\mathrm{S}, \gamma(\mathrm{G}))=\mathrm{k}$ \} .

The above two concepts are extended in the context of maximum independent sets.

\subsection{Definition}

Let $\mathrm{S}$ be a maximum independent set of $\mathrm{G}$. A subset $\mathrm{T}$ of $\mathrm{S}$ is called a forcing subset if $\mathrm{T}$ is contained in no other maximum independent subset in $\mathrm{G}$. The independent forcing number of $\mathrm{S}$ denoted by $f_{I}(G, S)$ is the cardinality of a minimum forcing subset of $\mathrm{S}$. The independent forcing number of $\mathrm{G}$ is the minimum of the independent forcing number of $\mathrm{S}$, where $\mathrm{S}$ is a maximum independent subset in $G$. The independent forcing spectrum of $G$ denoted by $\operatorname{Spec}_{I}(G)$ is defined as the set $\operatorname{Spec}_{\mathrm{I}}(\mathrm{G})=\{\mathrm{k}$ : there exists a maximum independent set $\mathrm{S}$ of $\mathrm{G}$ such that $\mathrm{f}_{\mathrm{I}}(\mathrm{G}, \mathrm{S})=\mathrm{k}$.

\subsection{Example}

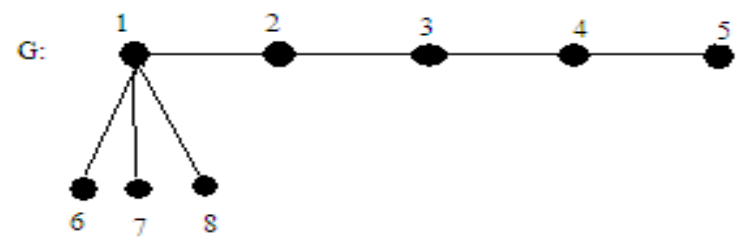


The maximum independent sets of $\mathrm{G}$ are $\{6,7,8,2,4\}$ (say $\mathrm{S}_{1}$ ), $\{6,7,8,2,5\}$ (say $S_{2}$ ) and $\{6,7,8,3,5\}$ (say $S_{3}$ ). In $S_{1}, 4$ is the only one vertex which is not contained in any other maximum independent set. Hence the specturum of $\mathrm{S}_{1}=\{1\}$. In $\mathrm{S}_{2},\{2,5\}$ is the subset of minimum cardinality which is not contained in any other maximum independent set. Hence the spectrum of $\mathrm{S}_{2}$ $=\{2\}$. In $\mathrm{S}_{3}, 3$ is the only one vertex which is not contained in any other maximum independent set. Hence the spectrum of $\mathrm{S}_{3}=\{1\}$. Hence $\operatorname{Spec}_{\mathrm{I}}(\mathrm{G})=\{1,2\}$.

\subsection{Remark}

If $\mathrm{G}$ has a unique maximum independent set, then

$\operatorname{Spec}_{\mathrm{I}}(\mathrm{G})=\{0\}$.

$\operatorname{Spec}_{l}(G)$ for some standard graphs

1. $\operatorname{Spec}_{\mathrm{I}}\left(\mathrm{K}_{\mathrm{n}}\right)=\{1\}$.

2. $\operatorname{Spec}_{\mathrm{I}}\left(\bar{K}_{n}\right)=\{0\}$.

3. $\operatorname{Spec}_{I}\left(K_{(1, n)}\right)=\{0\}$.

4. $\operatorname{Spec}_{\mathrm{I}}\left(\mathrm{K}_{(\mathrm{m}, \mathrm{n})}\right)= \begin{cases}\{0\}, & \mathrm{m} \neq \mathrm{n} \\ \{1\}, & \mathrm{m}=\mathrm{n}\end{cases}$

5. $\operatorname{Spec}_{I}\left(C_{n}\right)=\left\{\begin{array}{l}\{1\}, \text { if } n \text { is even } \\ \{2\}, \text { if } n \text { is odd }\end{array}\right.$

6. $\operatorname{Spec}_{\mathrm{I}}\left(\mathrm{D}_{\mathrm{m}, \mathrm{n}}\right)=0$, where $\mathrm{m}<\mathrm{n}$.

7. $\operatorname{Spec}_{I}\left(\mathrm{P}_{\mathrm{n}}\right)=\left\{\begin{array}{c}\{2\}, \text { if } n=4 \\ \{0\}, \text { if } \mathrm{n} \text { is odd } \\ \{1\}, \text { if } n \text { is even and } \mathrm{n} \neq 4\end{array}\right.$

8. $\operatorname{Spec}_{\mathrm{I}}\left(\mathrm{W}_{\mathrm{n}}\right)=\left\{\begin{array}{c}\{1\}, \text { if } \mathrm{n} \text { is odd } \\ \{2\}, \text { if } \mathrm{n} \text { is even }\end{array}\right.$

\subsection{Theorem}

Let $\mathrm{G}$ be a graph with $\operatorname{Spec}_{\mathrm{I}}(\mathrm{G})=\mathrm{A}$. Then for any integer $\mathrm{k}$, there exists a graph $H$ with $\operatorname{Spec}_{I}(H)=\{x+k: x \in A\}$.

\section{Proof}

Let $\mathrm{H}=\mathrm{GU} \mathrm{kC}_{4} . \operatorname{Spec}_{\mathrm{I}}(\mathrm{H})=\{\mathrm{x}+\mathrm{k}: \mathrm{x} \in \mathrm{A}\}$. Let $\mathrm{S}=\left\{\mathrm{u}_{1}, \mathrm{u}_{2} \ldots\right.$ $\left.\mathrm{u}_{\mathrm{r}}\right\}$ be a maximum independent set of $\mathrm{G}$ whose forcing independent number is $\mathrm{x}$. Let $\mathrm{v}_{\mathrm{i} 1}, \mathrm{v}_{\mathrm{i} 2}, \mathrm{v}_{\mathrm{i} 3}, \mathrm{v}_{\mathrm{i} 4}$ be the vertices of $\mathrm{i}$-th copy of $\mathrm{C}_{4}$ in the cyclic order. Then $\mathrm{S} U\left\{\mathrm{v}_{\mathrm{i} 1}, \mathrm{v}_{\mathrm{i} 3}: 1 \leq \mathrm{i} \leq\right.$ $\mathrm{k}\}$ is a maximum independent set of $\mathrm{H}$, for which the minimum forcing set is $\left\{\mathrm{u}_{\mathrm{j} 1}, \mathrm{u}_{\mathrm{j} 2}, \ldots, \mathrm{u}_{\mathrm{jx}}, \mathrm{v}_{\mathrm{i}}: 1 \leq \mathrm{i} \leq \mathrm{k}\right\}$, where $\left\{\mathrm{u}_{\mathrm{j} 1}, \mathrm{u}_{\mathrm{j} 2}\right.$, . . . , $\left.\mathrm{u}_{\mathrm{jx}}\right\}$ is an independent forcing set of $\mathrm{S}$ of minimum cardinality.

\subsection{Theorem}

There exists a graph $\mathrm{G}$ in which $\beta_{0}(G) \in \operatorname{Spec}_{\mathrm{I}}(\mathrm{G})$.

\section{Proof}

Let $\mathrm{H}$ be any connected graph. Let $\mathrm{G}=\mathrm{H} \circ \mathrm{K}_{1}$. Let $|\mathrm{V}(\mathrm{H})|=\mathrm{n}$. Let $\mathrm{T}=\left\{\mathrm{v}_{1}, \mathrm{v}_{2} \ldots \mathrm{v}_{\mathrm{n}}\right\}$ be the set of all pendant vertices of $\mathrm{G}$. Consider any proper subset $\mathrm{T}_{1}=\left\{\mathrm{v}_{\mathrm{i} 1}, \mathrm{v}_{\mathrm{i} 2}, \ldots, \mathrm{v}_{\mathrm{ij}}\right\}$ of $\mathrm{T} .(\mathrm{j}<\mathrm{n})$. Let $\mathrm{v}_{\mathrm{j}} \in \mathrm{T}-\mathrm{T}_{1}$. Then $\mathrm{T}_{2}=\left\{\mathrm{v}_{1}, \ldots, \mathrm{v}_{\mathrm{j}-1}, \mathrm{u}_{\mathrm{j}}, \mathrm{v}_{\mathrm{j}+1}, \ldots, \mathrm{v}_{\mathrm{n}}\right\}$ is a maximum independent subset of $G$ where $u_{j}$ is the support of $v_{j}$ in G. Thus $T_{1}$ is not in a forcing subset of $T$. Therefore $T$ is the only independent forcing subset of $\mathrm{T}$.

Therefore $\mathrm{f}_{\mathrm{I}}(\mathrm{G}, \mathrm{T})=\mathrm{n}=\beta_{0}(G)$.

\subsection{Observation}

There exists a graph $\mathrm{G}$ for which $\left.\operatorname{Spec}_{\mathrm{I}}(\mathrm{G})=\left\{1, \beta_{0}(G)\right)\right\}$.

For example, $\operatorname{Spec}_{\mathrm{I}}\left(\mathrm{K}_{\mathrm{n}} \circ \mathrm{K}_{1}\right)=\{1, \mathrm{n}\}$.

\subsection{Observation}

For any positive integer 'a', there exists a graph $\mathrm{G}$ with

$\operatorname{Spec}_{\mathrm{I}}(\mathrm{G})=\{\mathrm{a}, \mathrm{a}+1\}$. For example, take $\mathrm{G}=\mathrm{P}_{4} \mathrm{U}(\mathrm{a}-1) \mathrm{C}_{4}$.

\subsection{Definition}

Let $\mathrm{k}, \mathrm{n}$ be two positive integers, such that $2 \leq \mathrm{k} \leq \mathrm{n}$. Let $\mathrm{M}$ be a set with $n$ elements. The Kneser graph $\mathrm{H}(\mathrm{n}, \mathrm{k})$ is defined as the graph whose vertex set V is the set of all subsets of a $\mathrm{n}$-set of cardinality $\mathrm{k}$ and two vertices of $\mathrm{H}(\mathrm{n}, \mathrm{k})$ are adjacent if and only if the corresponding sets are disjoint.

\subsection{Theorem}

$\beta_{0}(\mathrm{H}(\mathrm{n}, 2))=\mathrm{n}-1$ and $\operatorname{Spec}_{\mathrm{I}}(\mathrm{H}(\mathrm{n}, 2))=\{2\}$

Proof

Let $S=\{1,2, \ldots, n\}$. Then $V(H(n, 2))=\left\{\left(x_{i}, x_{j}\right): x_{i}, x_{j} \in S, x_{i}\right.$ $\left.\neq \mathrm{x}_{\mathrm{j}}\right\}$. For any $\mathrm{x} \in \mathrm{S}, \mathrm{T}=\{(\mathrm{x}, \mathrm{y}): \mathrm{y} \in \mathrm{S}, \mathrm{y} \neq \mathrm{x}\}$ is an independent set in $H(n, 2)$. Therefore $\beta_{0}(H(n, 2)) \geq|T|=n-1$. Let $\mathrm{T}$ be any independent set of $(H(n, 2))$. Suppose (x, y) $\in \mathrm{T}$. Then $(\mathrm{u}, \mathrm{v}) \notin \mathrm{T}$, for all $\mathrm{u}, \mathrm{v} \notin\{\mathrm{x}, \mathrm{y}\}$. There are $(\mathrm{n}-2)$ - 
elements in $\mathrm{S}-\{\mathrm{x}, \mathrm{y}\}$. Thus $(\mathrm{n}-2) \mathrm{C}_{2}$ vertices in $\mathrm{H}(\mathrm{n}, 2)$ can not be in $\mathrm{T}$. Therefore $|\mathrm{T}| \leq \mathrm{nC}_{2}-\frac{(n-2)(n-3)}{2}=2 \mathrm{n}-3$. Let $(\mathrm{x}, \mathrm{y}) \mathrm{\epsilon}$ $\mathrm{T}$. Then any element of $\mathrm{T}$ is either $(\mathrm{x}, \mathrm{z})$ or $(\mathrm{y}, \mathrm{z})$. Let $(\mathrm{x}, \mathrm{z}) \in \mathrm{C}$.

Case(i): Suppose (y, z) $\in \mathrm{T}$. Then $|\mathrm{T}|=3$.

Case(ii): Suppose $(y, z) \notin T$. Then $(y, w) \notin T$, for all $w \neq\{x$, $\mathrm{y}\}$. That is, $\mathrm{T}$ does not contain $\mathrm{n}-2$ elements. Therefore $|\mathrm{T}| \leq$ $(2 n-3)-(n-2)=n-1$. Thus $|T| \leq \max \{3, n-1\}$. Therefore $\beta(H(n, 2)) \leq n-1$. Therefore $\beta_{0}(H(n, 2))=n-1$. From the above, we get that the only maximum independent sets of $\mathrm{H}(\mathrm{n}$, 2) are $\left\{\mathrm{u}_{\mathrm{r}}, \mathrm{u}_{\mathrm{i}}: 1 \leq \mathrm{i} \leq \mathrm{n}, \mathrm{i} \neq \mathrm{r}, \mathrm{u}_{\mathrm{r}}\right.$ fixed $\}$.

Therefore, $\operatorname{Spec}_{\mathrm{I}}(\mathrm{H}(\mathrm{n}, 2))=\{2\}$.

\subsection{Observation}

$\operatorname{Spec}_{\mathrm{I}}\left(\mathrm{P}_{\mathrm{m}} \square \mathrm{P}_{\mathrm{n}}\right)=\left\{\begin{array}{c}\{0\}, \quad \text { if } \mathrm{mn} \equiv 1(\bmod 2) \\ \{1\}, \text { otherwise }\end{array}\right.$

\section{Proof:}

If $\mathrm{mn} \equiv 1(\bmod 2)$, then $\mathrm{P}_{\mathrm{m}} \square \mathrm{P}_{\mathrm{n}}$ contains a unique maximum independent set of cardinality $\left\lceil\frac{m n}{2}\right\rceil$.Therefore $\operatorname{Spec}_{\mathrm{I}}\left(\mathrm{P}_{\mathrm{m}} \square \mathrm{P}_{\mathrm{n}}\right)$ $=\{0\}$. If $\mathrm{mn} \equiv 0(\bmod 2)$, then $\mathrm{P}_{\mathrm{m}} \square \mathrm{P}_{\mathrm{n}}$ contains exactly two maximum independent sets of cardinality $\frac{m n}{2}$ and each vertex is contained in a unique maximum independent set. Therefore $\operatorname{Spec}_{\mathrm{I}}\left(\mathrm{P}_{\mathrm{m}} \square \mathrm{P}_{\mathrm{n}}\right)=\{1\} . \operatorname{Spec}_{\mathrm{I}}\left(\mathrm{P}_{\mathrm{m}} \square \mathrm{P}_{\mathrm{n}}\right)=\{0\}$.

\subsection{Theorem}

Given any three positive integers $a+1, a+2, a+3, a \geq 0$, there exists a graph $G$ with $\operatorname{Spec}_{I}(G)=\{a+1, a+2, a+3\}$.

Proof:

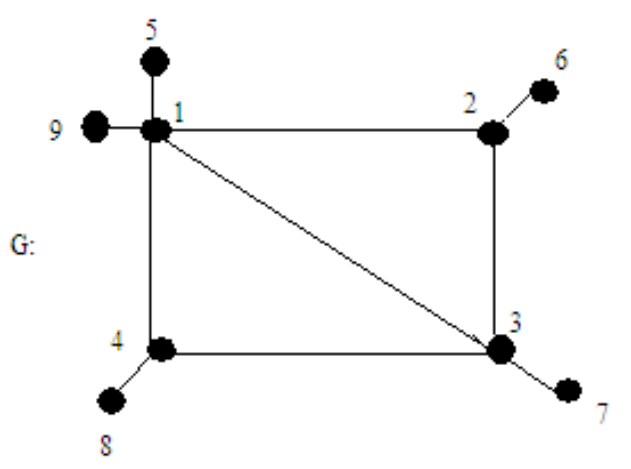

Consider the graph $\mathrm{H}=\mathrm{GU} \mathrm{aC}$, where $\mathrm{a} \geq 0$. Then $\operatorname{Spec}_{\mathrm{I}}(\mathrm{G})=$ $\{\mathrm{a}+1, \mathrm{a}+2, \mathrm{a}+3\}$. The maximum independent sets of $\mathrm{G}$ are $\mathrm{S}_{1}=\{3,5,6,8,9\}, \mathrm{S}_{2}=\{4,5,6,7,9\}, \mathrm{S}_{3}=\{5,6,7,8,9\}$,
$\mathrm{f}_{\mathrm{I}}\left(\mathrm{G}, \mathrm{S}_{1}\right)=1, \mathrm{f}_{\mathrm{I}}\left(\mathrm{G}, \mathrm{S}_{2}\right)=2, \mathrm{f}_{\mathrm{I}}\left(\mathrm{G}, \mathrm{S}_{3}\right)=3$

Hence $\operatorname{Spec}_{\mathrm{I}} \mathrm{G}=\{1,2,3\}$.

\subsection{Result}

Let $\mathrm{G}$ be the graph obtained by joining exactly two vertices one each from two vertex disjoint complete graphs. Then $\operatorname{Spec}_{I}(G)$ $=\{2\}$.

\section{Proof}

Let $K_{n}$ and $K_{m}$ be any two complete graphs with vertex sets $\left\{u_{1}\right.$, $\left.\mathrm{u}_{2}, \ldots, \mathrm{u}_{\mathrm{n}}\right\}$ and $\left\{\mathrm{v}_{1}, \mathrm{v}_{2}, \ldots, \mathrm{v}_{\mathrm{m}}\right\}$ respectively. Join a vertex of $K_{n}$ say $u_{i}, 1 \leq i \leq n$ with any one vertex of $K_{m}$ say $v_{j}, 1 \leq j \leq m$. Let the resulting graph be denoted by $G$. Now the maximum independent sets are $\left\{\mathrm{u}_{1}, \mathrm{v}_{\mathrm{j}}\right\}, 1 \leq \mathrm{j} \leq \mathrm{m}$ or $\left\{\mathrm{u}_{2}, \mathrm{v}_{\mathrm{j}}\right\}, 1 \leq \mathrm{j} \leq \mathrm{m}$ or . . ., $\left\{\mathrm{u}_{\mathrm{n}}, \mathrm{v}_{\mathrm{j}}\right\}, 1 \leq \mathrm{j} \leq \mathrm{m}$ or $\left\{\mathrm{u}_{\mathrm{i}}, \mathrm{v}_{1}\right\}, 1 \leq \mathrm{i} \leq \mathrm{n}$ or $\left\{\mathrm{u}_{\mathrm{i}}, \mathrm{v}_{2}\right\}, 1 \leq \mathrm{i} \leq \mathrm{n}, \ldots$. $\left\{\mathrm{u}_{\mathrm{i}}, \mathrm{v}_{\mathrm{m}}\right\}, 1 \leq \mathrm{i} \leq \mathrm{n}$. Hence $\operatorname{Spec}_{\mathrm{I}}(\mathrm{G})=\{2\}$.

\subsection{Definition}

From a graph G, by Mycielski's construction, one can get a graph $\mu(G)$, with $V(\mu(G)=V \cup \mathbf{U} \cup\{\mathbf{w}\}$, where: $V=V(G)=$ $\left\{\mathrm{v}_{1}, \mathrm{v}_{2}, \ldots, \mathrm{v}_{\mathrm{n}}\right\} ; \quad \mathbf{U}=\left\{\mathrm{u}_{1}, \mathrm{u}_{2}, \ldots, \mathrm{u}_{\mathrm{n}}\right\}$ and $\mathrm{E}(\mu(\mathrm{G}))=\mathrm{E}(\mathrm{G}) \mathrm{U}$ $\left\{\mathrm{u}_{\mathrm{i}} \mathrm{v}: \mathrm{v} \in \mathrm{N}_{\mathrm{G}}\left(\mathrm{v}_{\mathrm{i}}\right)\right\} \cup\left\{\mathrm{u}_{\mathrm{i}} \mathrm{W}: 1 \leq \mathrm{i} \leq \mathrm{n}\right\}$. For each $0 \leq \mathrm{i} \leq \mathrm{n}$, $v_{i}$ and $u_{i}$ are called the corresponding Vertices of $\mu(G)$.

\subsection{Theorem}

Let $|\mathrm{V}(\mathrm{G})|=\mathrm{n} \geq 3$. Then $\beta_{0}(\mu(G))>\max \left\{|V(G)|, 2 \beta_{0}(G)\right\}$ if and only if $\mathrm{G}$ is constructed as follows: Start with $\overline{K_{n}}$. Choose a subset S of vertices of $\overline{K_{n}}$ of cardinality s and a subset $\mathrm{R}$ of $\mathrm{S}$ of cardinality $\mathrm{r} \leq \mathrm{s}-3$ such that $\mathrm{r}+\mathrm{s}>\mathrm{n}$. Draw at least one edge from each vertex of $\mathrm{V}-\mathrm{S}$ to the vertices of $\mathrm{R}$ .Draw edges such that $\beta_{0}(G)<\frac{n+t}{2}$ where $\mathrm{t}=\mathrm{r}+\mathrm{s}-\mathrm{n}$.

Proof

Let $\mathrm{V}(\mathrm{G})=\left\{\mathrm{u}_{1}, \mathrm{u}_{2} \ldots \mathrm{u}_{\mathrm{n}}\right\}$ and $\mathrm{V}(\mu(\mathrm{G}))=\left\{\mathrm{u}_{1}, \mathrm{u}_{2} \ldots \mathrm{u}_{\mathrm{n}}, \mathrm{u}_{1}{ }^{\prime}, \mathrm{u}_{2}{ }^{\prime} \ldots \mathrm{u}_{\mathrm{n}}{ }^{\prime}, \mathrm{v}\right\}$. Let $\beta_{0}(G \mu(G))=n+t$ where $2 \beta_{0}(G)<\mathrm{n}+\mathrm{t}$. Since $|\mathrm{V}(\mathrm{G})| \geq 3, \mathrm{v}$ does not belong to any $\beta_{0}$ set of $\mu(G)$, then $\mathrm{S} \cap \mathrm{V}(\mathrm{G}) \neq \phi$. Let $\mathrm{S} \cap \mathrm{V}(\mathrm{G})=\mathrm{r} \geq 1$. Let $\mathrm{S} \cap \mathrm{V}^{\prime}(\mathrm{G})=\mathrm{s} \geq 1$. Suppose $\mathrm{S}_{1}=\mathrm{S} \cap \mathrm{V}(\mathrm{G})$ and $\mathrm{T}^{\prime}=\mathrm{S} \cap \mathrm{V}^{\prime}(\mathrm{G})$. Let $\mathrm{T}$ be the set of corresponding vertices of $T^{\prime}$. Suppose $\mathrm{T} \mathrm{S}_{1}=\phi$. Then | $\mathrm{T} \cup \mathrm{S}_{1}|=| \mathrm{T}|+| \mathrm{S}_{1}|=| \mathrm{T}^{\prime}|+| \mathrm{S}_{1} \mid=\mathrm{s}+\mathrm{r} \leq \mathrm{n}\left(\right.$ since $\mathrm{T} \cup \mathrm{S}_{1}$ is a subset of $\mathrm{V}(\mathrm{G})$ ). Therefore $\mathrm{n}+\mathrm{t} \leq \mathrm{n}$ implies $\mathrm{t} \leq 0$, a contradiction. Suppose $\mathrm{S}_{1}$ is not contained in $\mathrm{T}$. Let $\mathrm{T}=\left\{\mathrm{u}_{\mathrm{i} 1}, \mathrm{u}_{\mathrm{i} 2}, \ldots \mathrm{u}_{\mathrm{ir}}\right\}$ where $\mathrm{S}_{1}-\mathrm{T} \neq \Phi$. Let without loss of generality $\mathrm{u}_{1} \in \mathrm{S}_{1}$-T.Let $\mathrm{W}=\mathrm{T}^{\prime} \cup\left\{\mathrm{u}^{\prime}{ }_{\mathrm{i} 1}\right\}$. Therefore, $\mathrm{W} \cup \mathrm{T}$ is independent in $\mu(\mathrm{G})$ of cardinality $\mathrm{r}+\mathrm{s}+1$, a contradiction. Therefore, $\mathrm{S}_{1}-\mathrm{T}=\Phi$. That is, $\mathrm{S}_{1} \subseteq \mathrm{T}$. Suppose $\mathrm{r} \geq$ s. $\mathrm{r}+\mathrm{s}=\mathrm{n}+\mathrm{t} \leq 2 \mathrm{r}$. That is, $\mathrm{n}+\mathrm{t} \leq 2 \beta_{0}(\mathrm{G})\left(\right.$ Since $\left.\mathrm{r} \leq \beta_{0}(\mathrm{G})\right)$, a 
contradiction, since $2 \beta_{0}(\mathrm{G}) \leq \mathrm{n}+\mathrm{t}$. Therefore, $\mathrm{r}<\mathrm{s}$. Thus, $2 \beta_{0}(\mathrm{G})<\mathrm{r}+\mathrm{s}<2 \mathrm{~s}$. Therefore, $\beta_{0}(\mathrm{G})<\mathrm{s}$ implies $\quad \mathrm{r} \leq \beta_{0}(\mathrm{G})$ $<$ s. Let $\mathrm{T}^{\prime}=\mathrm{S} \cap \mathrm{V}^{\prime}(\mathrm{G})=\left\{\mathrm{u}_{1}{ }^{\prime}, \mathrm{u}_{2}{ }^{\prime}, \ldots . . \mathrm{u}_{\mathrm{s}}{ }^{\prime}\right\}$. Thus $\mathrm{T}=\left\{\mathrm{u}_{1}, \mathrm{u}_{2}, \ldots . . \mathrm{u}_{\mathrm{s}}\right\}$. Since $\mathrm{S}_{1} \subseteq \mathrm{T}$, let without loss of generality, $\mathrm{S}_{1}=\left\{\mathrm{u}_{1}, \mathrm{u}_{2}, \ldots . . \mathrm{u}_{\mathrm{r}}\right\}, \mathrm{r}<\mathrm{s}$. Let $\mathrm{U}=\left\{\mathrm{u}_{\mathrm{r}+1}, \ldots \mathrm{u}_{\mathrm{s}}\right\}$. Then $|\mathrm{U}|=$ s-r. Let $\mathrm{H}$ be the sub graph of $\mathrm{G}$ induced by $U$. Every vertices of $U$ is not adjacent to any vertex of $S_{1}$, for otherwise, $S$ will not be independent. Let $\beta_{0}(<\mathrm{U}>)=\alpha \geq 1$. Therefore, $\beta_{0}(\mathrm{G}) \geq \alpha+\mathrm{r}$. Therefore, $2 \beta_{0}(\mathrm{G}) \geq 2(\alpha+\mathrm{r})<\mathrm{r}+\mathrm{s}$ implies $\alpha<\frac{s-r}{2}$. But $\alpha \geq 1$. Therefore, s-r $>2 \mathrm{r} \geq 2$. Therefore, $\mathrm{s} \geq \mathrm{r}+3$. Therefore, $\left|\mathrm{T}-\mathrm{S}_{1}\right| \geq 3$. since $\mathrm{r} \leq \mathrm{s}-3, \mathrm{r}+\mathrm{s}=\mathrm{n}+\mathrm{t}$ gives $\mathrm{r}=\mathrm{n}+\mathrm{t}-\mathrm{s} \leq \mathrm{s}-3$. Therefore, $\mathrm{n}+\mathrm{t} \leq 2 \mathrm{~s}-3$ implies $2 \mathrm{~s} \geq \mathrm{n}+\mathrm{t}+3$. Therefore, $\mathrm{s} \geq \frac{n+t+s}{2}$. But $\mathrm{s}$ $\leq \mathrm{n}$. Therefore, $\frac{n+t+3}{2} \leq \mathrm{s} \leq \mathrm{n}$. Therefore, $\mathrm{t}+\mathrm{s} \leq \mathrm{n}$ implies $\mathrm{t} \leq \mathrm{n}$ 3.Thus $\mathrm{n}+\mathrm{t} \leq 2 \mathrm{n}-3$. Therefore, $\beta_{0}(\mu(G)) \leq 2 n-3$. Choose any subset $R^{\prime}$ of $V^{\prime}(G)$ such that $\left|R^{\prime}\right|=s$ and $s \leq n$. Let $R$ be the corresponding vertices of $R^{\prime}$ in $V(G)$.let $X$ be a subset of $R$ of cardinality $r$ such that $r+s=n+t, t \geq 1$. Since $r \leq s-3$, there are at least three vertices in $\mathrm{R}-\mathrm{X}$. Let $\mathrm{U}=\mathrm{R}-\mathrm{X}$ and $\mathrm{Y}=\mathrm{V}-\mathrm{R}$. There is no edge between $\mathrm{Y}$ and $\mathrm{U}$. Every vertex of $\mathrm{Y}$ is adjacent to at least one vertex of $R$.

For : otherwise, if there exist a vertex $y \in Y$ such that $y$ is not adjacent to any vertex of $R$, then $T^{\prime} \cup\{y\} \cup R$ IS an independent set of $\mu(G)$ of cardinality $\mathrm{s}+1+\mathrm{r}$, a contradiction . Draw edges between $R$ and $U$ and between Rand $Y$ such that $\beta_{0}(G)<$ $\frac{n+t}{2}$. Then $\beta\left(\mu(\mathrm{G})>\max \left\{|\mathrm{V}(\mathrm{G})|, 2 \beta_{0}(\mathrm{G})\right\}\right.$. It is easily seen that the construction described in the theorem gives rise to a graph for which $\beta\left(\mu(G)>\max \left\{|V(G)|, 2 \beta_{0}(G)\right\}\right.$ and if this condition is satisfied then $G$ comes out from $K_{n}$ in the manner in which the construction is done. Hence the theorem.

\subsection{Theorem}

Let $\mathrm{n}=10$. To construct a graph $\mathrm{G}$ of order 10 such that $\beta_{0}(\mu$ $(G))=12$ and $\beta_{0}(G)=5$. consider $K_{10}$ with $V\left(K_{10}\right)=\left\{u_{1}, u_{2}, \ldots u_{10}\right\}$. let $\mathrm{R}=\left\{\mathrm{u}_{1}, \mathrm{u}_{2}, \ldots \mathrm{u}_{8}\right\}$ and $\mathrm{X}=\left\{\mathrm{u}_{1}, \mathrm{u}_{2}, \mathrm{u}_{3}, \mathrm{u}_{4}\right\}$.U $\mathrm{U}=\mathrm{R}-$ $\mathrm{X}=\left\{\mathrm{u}_{5}, \mathrm{u}_{6}, \mathrm{u}_{7}, \mathrm{u}_{8}\right\} . \mathrm{Y}=\mathrm{V}-\mathrm{R}=\left\{\mathrm{u}_{9}, \mathrm{u}_{10}\right\}$. Draw at least one edge from each of $u_{9}, u_{1} 0$ to $R$. Draw edges between $X$ and $U$ and among $\mathrm{U}$ such that $\beta_{0}$ of the resulting graph is 5. Then $\left\{\mathrm{u}_{1}{ }^{\prime}, \mathrm{u}_{2}{ }^{\prime}, \ldots \mathrm{u}_{8}{ }^{\prime}, \mathrm{u}_{1}, \mathrm{u}_{2}, \mathrm{u}_{3}, \mathrm{u}_{4}\right\}$ is a maximum independent set of $\mu(\mathrm{G}) . \beta(\mu(\mathrm{G}))=12>\max \left\{|\mathrm{V}(\mathrm{G})|, 2 \beta_{0}(\mathrm{G})\right\}$.

\subsection{Theorem}

Let $\mathrm{G}$ be a graph of order n. Let $\beta_{0}(\mu(G))=\max \left\{2 \beta_{0}(\mathrm{G}), \mathrm{n}\right\}$ and let $\beta_{0}(\mathrm{G})=\frac{n}{2}$. Then $\operatorname{Spec}_{\mathrm{I}}(\mu(\mathrm{G}))=\operatorname{Spec}_{\mathrm{I}}(\mathrm{G}) \cup\{\alpha\}$ where $\alpha$ is 1 or $2 . \alpha$ is 1 iff there exists a vertex in G which is not contained in any maximum independent set.

\section{Proof:}

Suppose $\quad \beta_{0}(\mathrm{G})=\frac{n}{2}$ (that is $\mathrm{n}$ is even).For any maximum independent set $S$ of $G, S \cup S^{\prime}$ is a maximum independent set of $\mu(G)$, where $S^{\prime}=\left\{x^{\prime}: x \square S\right\}$. Also $V^{\prime}$ is a maximum independent set of $\mu(\mathrm{G})$. Since $\beta_{0}(\mathrm{G})=\frac{n}{2}, \mathrm{G} \neq \overline{K_{n}}$. Therefore there exists at least one edge in $\mathrm{G}$.

Case (i): Any vertex in $G$ is contained in a maximum independent set of $G$. Then any $u^{\prime} \in V^{\prime}(\mu(G))$ is contained in two maximum independent sets of $\mu(G)$ namely $V^{\prime}$ and $I-\{u\} U$ $\left\{u^{\prime}\right\}$, where $I$ is the maximum independent set containing $u$. Also, if $\mathrm{u}, \mathrm{v}$ are adjacent in $\mathrm{V}$, then $\mathrm{u}^{\prime}, \mathrm{v}^{\prime}$ are contained in the unique maximum independent set of $\mu(G)$, namely $V^{\prime}$. Therefore the forcing number of $\mathrm{V}^{\prime}$ is 2 .

Case (ii): There exists a vertex $u$ in $G$ which is not contained in a maximum independent set of $G$. Then $u^{\prime}$ is contained in a unique maximum independent set of $\mu(G)$, namely $V^{\prime}$. Therefore the forcing number of $\mathrm{V}^{\prime}$ is 1.Let $\mathrm{I}$ be any maximum independent set of $\mu(\mathrm{G})$ different from $V^{\prime}$. Then $I=S$ U S', where $S$ is a maximum independent set of $G$. Any forcing independent subset of $\mathrm{S}$ in $\mathrm{G}$ is also a forcing independent subset of $I$ in $\mu(G)$. Any subset of $S^{\prime}$ is not a forcing ind/ependent subset of I since $\mathrm{S}^{\prime}$ is contained in $\mathrm{V}^{\prime}$. Let $\mathrm{T} \subseteq \mathrm{S}$ and $\mathrm{T}_{1} \subseteq \mathrm{S}^{\prime}$. Suppose $\mathrm{T} \mathrm{U} \mathrm{T}_{1}$ is a forcing independent subset of $S$ U S' in $\mu(G)$. Then $T$ is a forcing independent subset of $S$ in $G$ and hence a forcing independent subset of S U S' in $\mu(\mathrm{G})$. But $|\mathrm{T}|$ $<\left|\mathrm{T} \mathrm{U} \mathrm{T}_{1}\right|$, a contradiction. Therefore, the forcing independence number of $S \mathrm{U}^{\prime}$ in $\mu(\mathrm{G})$ coincides with the forcing independence number of $\mathrm{S} \in \mathrm{G}$. Hence the theorem

\subsection{Theorem}

$4 \notin \operatorname{Spec}_{\mathrm{I}}\left(\mathrm{C}_{5}\right.$ o $\left.\mathrm{k}_{1}\right)$

Proof:

Any maximum independent set of $\mathrm{C}_{5} \mathrm{O} \mathrm{k}_{1}$ is one of the following types

(i)All pendant vertices.

(ii)Single vertex from $\mathrm{C}_{5}$ and 4 pendant vertices attached to the other vertices of $\mathrm{C}_{5}$.

(iii)Two vertices from $\mathrm{C}_{5}$ and 3 pendant vertices attached to the other vertices of $\mathrm{C}_{5}$.

The maximum independent set formed by type (i) has forcing independence number 5 . The maximum independent set formed by type (ii) has forcing independence number 2 . 
The maximum independent set formed by type (iii) has forcing independence number 3.Therefore $\operatorname{Spec}_{\mathrm{I}}\left(\mathrm{C}_{5} \circ \mathrm{k}_{1}\right)=\{1,3,5\}$.

Hence $4 \notin \operatorname{Spec}_{\mathrm{I}}\left(\mathrm{C}_{5}\right.$ o $\left.\mathrm{k}_{1}\right)$.

\subsection{Theorem}

$\operatorname{Spec}_{I}\left(C_{(2 n)} \circ K_{1}\right)=\{n, n+1, \ldots,(2 n-2), 2 n\}$.

Proof

Consider $\mathrm{C}_{2 \mathrm{n}} \circ \mathrm{K}_{1}$. Any $\beta_{0}$-set of $\mathrm{C}_{2 \mathrm{n}} \circ \mathrm{K}_{1}$ is one of the following types.

(i) All pendant vertices of $\mathrm{C}_{2 \mathrm{n}} \circ \mathrm{K}_{1}$.

(ii) $\mathrm{k}$ independent vertices from $\mathrm{C}_{2 \mathrm{n}}$ and $\mathrm{n}-\mathrm{k}$ pendant vertices attached to other vertices of $C_{2 n},(1 \leq k \leq n)$.

The maximum independent set formed by type(i) has forcing independence number $2 \mathrm{n}$. The maximum independent set of type(ii) has forcing independence number $2 \mathrm{n}-(\mathrm{k}+1)$, if $\mathrm{k} \leq \mathrm{n}-$ 1 and $\mathrm{n}$ if $\mathrm{k}=\mathrm{n}$.

\subsection{Remark}

$\operatorname{Spec}_{I}\left(C_{(2 n+1)} \circ K_{1}\right)=\{n, n+1, \ldots,(2 n-1),(2 n+1)\}$.

\subsection{Remark}

$\left|\operatorname{Spec}_{\mathrm{I}}\left(\mathrm{C}_{\mathrm{n}} \circ \mathrm{K}_{1}\right)\right|=\left\lceil\frac{n}{2}\right\rceil$

\subsection{Result}

Let $\mathrm{G}=\mathrm{G}_{1} \cup \mathrm{G}_{2}$.. Then $\operatorname{Spec}_{\mathrm{I}}\left(\mathrm{G}_{1} \mathrm{UG}_{2}\right)=\{\mathrm{x}: \mathrm{x}=\mathrm{y}+\mathrm{z}, \mathrm{y} \mathrm{C}$ $\operatorname{Spec}_{\mathrm{I}}\left(\mathrm{G}_{1}\right)$, z $\left.\in \operatorname{Spec}_{\mathrm{I}}\left(\mathrm{G}_{2}\right)\right\}$.

\section{Proof:}

Let y $\in \operatorname{Spec}_{\mathrm{I}}\left(\mathrm{G}_{1}\right)$ and $\mathrm{z} \in \operatorname{Spec}_{\mathrm{I}}\left(\mathrm{G}_{2}\right)$. Let $\left\{\mathrm{u}_{1}, \mathrm{u}_{2}, \ldots, \mathrm{u}_{\mathrm{t}}\right\}$ be a maximum independent set of $G_{1}$ with forcing independent number $y$ and $\left\{v_{1}, v_{2}, \ldots, v_{s}\right\}$ be a maximum independent set of $\mathrm{G}_{2}$ with forcing independence number $\mathrm{z}$. Then $\left\{\mathrm{u}_{1}, \mathrm{u}_{2}, \ldots, \mathrm{u}_{\mathrm{t}}\right.$, $\mathrm{v}_{1}, \mathrm{v}_{2}, \ldots, \mathrm{v}_{\mathrm{s}}$ \} is a maximum independent set of $\mathrm{G}_{1} \mathrm{U} \mathrm{G}_{2}$ with forcing independence number $\mathrm{y}+\mathrm{z}$. Therefore $\mathrm{y}+\mathrm{z} \in \operatorname{Spec}_{\mathrm{I}}\left(\mathrm{G}_{1}\right.$ $\cup \mathrm{G}_{2}$ ).

Any maximum independent set $I$ of $G_{1} U_{G_{2}}$ is the union of maximum independent set $\mathrm{I}_{1}$ of $\mathrm{G}_{1}$ and a maximum independent set $I_{2}$ of $G_{2}$. That is $I=I_{1} \cup I_{2}$. Let $k$ be the forcing independence number of $I$. Any forcing independent subset of $I_{1}$ combined with any forcing independent set of $I_{2}$ is a forcing independent set of $\mathrm{I}$. Let $\mathrm{I}=\left\{\mathrm{u}_{1}, \mathrm{u}_{2}, \ldots, \mathrm{u}_{\mathrm{t} 1}, \mathrm{v}_{1}, \mathrm{v}_{2}, \ldots, \mathrm{v}_{\mathrm{t} 2}\right\}$, where $u_{1}, u_{2}, \ldots, u_{t 1} \in I_{1}$ and $v_{1}, v_{2}, \ldots, v_{t 2} \in I_{2}$. Let $\left\{u_{i 1}, u_{i 2}\right.$, $\left.\ldots u_{\mathrm{ir} 1}, v_{\mathrm{j} 1}, v_{\mathrm{j} 2}, \ldots, v_{\mathrm{j} 2}\right\}$ is a forcing independent subset of $I$ of cardinality k. Clearly $\left\{\mathrm{u}_{\mathrm{i} 1}, \mathrm{u}_{\mathrm{i} 2}, \ldots \mathrm{u}_{\mathrm{ir} 1}\right\}$ is forcing in $\mathrm{I}_{1}$ and $\left\{\mathrm{v}_{\mathrm{j} 1}\right.$ $\left., \mathrm{v}_{\mathrm{j} 2}, \ldots, \mathrm{v}_{\mathrm{jr} 2}\right\}$ is forcing in $\mathrm{I}_{2}$. Therefore $\mathrm{k}=\mathrm{r}_{1}+\mathrm{r}_{2}$, where $\mathrm{r}_{1} \in \operatorname{Spec}_{\mathrm{I}}\left(\mathrm{G}_{1}\right)$ and $\mathrm{r}_{2} \in \operatorname{Spec}_{\mathrm{I}}\left(\mathrm{G}_{2}\right)$.

\subsection{Result}

$\operatorname{Spec}_{\mathrm{I}}\left(\mathrm{C}_{\mathrm{n}}\right) \cup \operatorname{Spec}_{\mathrm{I}}\left(\bar{C}_{n}\right)=\left\{\begin{array}{c}\{0,1\} \text { if } \mathrm{n}=3 \\ \{1,2\} \text { if } \mathrm{n} \geq 4, \mathrm{n} \text { even } \\ \{2\} \text { if } \mathrm{n} \geq 5 \text { and } \mathrm{n} \text { odd }\end{array}\right.$

Proof:

$\operatorname{Spec}_{\mathrm{I}}\left(\mathrm{C}_{\mathrm{n}}\right)=\left\{\begin{array}{c}\{1\} \text { if } \mathrm{n} \text { is even, } \mathrm{n} \geq 4 \text { (or) } \mathrm{n}=3 . \\ \{2\} \text { if } \mathrm{n} \geq 5, \mathrm{n} \text { odd }\end{array}\right.$

Let $\mathrm{n} \geq 5$. Then $\beta_{0}\left(\bar{C}_{n}\right)=2$. Any vertex of $\bar{C}_{n}$ is contained in two maximum independent set of $\mathrm{C}_{\mathrm{n}}$. Therefore $\operatorname{Spec}_{\mathrm{I}}\left(\mathrm{C}_{\mathrm{n}}\right)=$ $\{2\}$.Also, $\operatorname{Spec}_{\mathrm{I}}\left(\bar{C}_{4}\right)=\{2\}$.

Hence $\operatorname{Spec}_{\mathrm{I}}\left(\mathrm{C}_{\mathrm{n}}\right) \cup \operatorname{Spec}_{\mathrm{I}}\left(\bar{C}_{n}\right)=\left\{\begin{array}{c}\{0,1\} \text { if } \mathrm{n}=3 \\ \{1,2\} \text { if } \mathrm{n} \geq 4, \mathrm{n} \text { even } \\ \{2\} \text { if } \mathrm{n} \geq 5 \text { and } \mathrm{n} \text { odd }\end{array}\right.$

\subsection{Remark}

Given any positive integer $\mathrm{k}$, there exists a graph $\mathrm{G}$ such that $\beta_{0}(G)-\left|\operatorname{Spec}_{\mathrm{I}}(\mathrm{G})\right|=\mathrm{k}$. For: $\beta_{0}\left(\mathrm{C}_{(2 \mathrm{k}+2)}\right)=\mathrm{k}+1$. $\left|\operatorname{Spec}_{\mathrm{I}}\left(\mathrm{C}_{2 \mathrm{k}+2}\right)\right|=$ 1 .

\subsection{Remark}

$\operatorname{Spec}_{\mathrm{I}}(\mathrm{G}) \leq \beta_{0}(\mathrm{G}) \leq \mathrm{n}-\chi(\mathrm{G})+1\left(\right.$ since $\left.\chi(\mathrm{G}) \leq \mathrm{n}-\beta_{0}(\mathrm{G})+1\right)$.

\subsection{Theorem}

Let $G_{1}$ and $G_{2}$ be two simple graphs. Let without loss of generality, $\beta_{0}\left(G_{1}\right) \leq \beta_{0}\left(G_{2}\right)$. Then $\operatorname{Spec}_{I}\left(G_{1}+G_{2}\right)=\operatorname{Spec}_{I}\left(G_{2}\right)$.

Proof:

Since $\beta_{0}\left(G_{1}+G_{2}\right)=\max \left(\beta_{0}\left(G_{1}\right), \beta_{0}\left(G_{2}\right)\right.$ and $\beta_{0}\left(G_{1}\right) \leq \beta_{0}\left(G_{2}\right)$, we have $\operatorname{Spec}_{\mathrm{I}}\left(\mathrm{G}_{1}+\mathrm{G}_{2}\right)=\operatorname{Spec}_{\mathrm{I}}\left(\mathrm{G}_{2}\right)$.

\subsection{Result}

$\beta_{0}(G) \in \operatorname{Spec}_{\mathrm{I}}(\mathrm{G})$ if and only if there exists a maximum independent set $I$ in $G$ such that for every vertex $u$ in $I$, there 
exists a vertex $u^{\prime} \notin I$ such that $(I--\{u\}) U u^{\prime}$ is independent.

\section{Proof:}

Suppose there exists a $\beta_{0}$-set I satisfying the hypothesis. Then given any proper subset $\mathrm{J}$ of $\mathrm{I}$, there exists $\mathrm{w} \in \mathrm{I}-\mathrm{J}$ and for this $\mathrm{w}$, there exists $\mathrm{w}^{\prime} \notin \mathrm{I}$ such that $\mathrm{I}^{\prime}=(\mathrm{I}-\{\mathrm{w}\}) \mathrm{U}\left\{\mathrm{w}^{\prime}\right\}$ is a $\beta_{0}$-set. Clearly $\mathrm{J}$ is contained in $\mathrm{I}$ as well as I'. Therefore no proper subset of $I$ is a forcing independent set of $I$. Therefore $\beta_{0}(G) €$ $\operatorname{Spec}_{\mathrm{I}}(\mathrm{G})$. Conversely, let $\beta_{0}(\mathrm{G}) \in \operatorname{Spec}_{\mathrm{I}}(\mathrm{G})$. Then there exists a $\beta_{0}$-set I such that any proper subset of $\mathrm{I}$ is not a forcing independent set of I. Let $u \in I$. Then $I-\{u\}$ is not a forcing independent set of I. Therefore $\mathrm{I}-\{\mathrm{u}\}$ is contained in a $\beta_{0}$-set I'. Since $|I-\{u\}|=\beta_{0}-1$ and $\left|I^{\prime}\right|=\beta_{0}$, there exists $u^{\prime} \in I^{\prime}$, $u^{\prime} \notin I$ such that $(I-\{u\}) U\left\{u^{\prime}\right\}=I^{\prime}$.

\subsection{Corollary}

If $\beta_{0}\left(G_{1}\right) \in \operatorname{Spec}_{I}(G)$ and $\beta_{0}\left(G_{2}\right) \in \operatorname{Spec}_{I}\left(G_{2}\right)$, then $\beta_{0}\left(G_{1} U G_{2}\right) €$ $\operatorname{Spec}_{\mathrm{I}}\left(\mathrm{G}_{1} \mathrm{U} \mathrm{G}_{2}\right)$.

\section{REFERENCES}

[1] P. Afshania, H. Hatamia and E.S. Mahmoodian, On the spectrum of the forced matching number of graphs, Australas. J. Combin. 30(2004), 147.
[2] Gary Chartrand, Heather Gavlas and Robert C.Vandell, The Forcing domination number of a graph , JCMCC 25 (1997), 161-174.

[3] Terasa W. Haynes, Stephen T. Hedetneimi, Peter J. Slater," Fundamentals of Domination in Graphs", Marcel Dekker Inc. (1998).

[4] P.Adams, M.Mahdian and E.S. Mahmoodian, On the forced matching member of graphs, preprint".

[5] G.Chartrand and P.Zhang, The forcing geodetic number of a graph".Dicsuss. math. graph theory,19(1999),pp:45-58.

[6] M.E.Riddle, The minimum forcing number for the forus and hyper cube, preprint.

[7] T.W.Heynes, S.T.Hedetneimi, P.J.Slater, Domination in graphs, Advanced topics, Marcel Dekker., Inc.,(1998).

[8] T.W.Heynes, S.T.Hedetneimi, P.J.Slater, Fundamentals of Domination in graphs, Marcel Dekker., Inc.,(1998).

[9] F.Harray, Graph theory, Addition Wesley, Reading Mass (1972). 